\title{
Ultrasonographic evaluation of acute appendicitis
}

\author{
RICHARD G. SHINBROT, DO
}

H. ROSS MILLER, DO

Twenty-one patients with a clinical diagnosis of acute appendicitis underwent graded compression ultrasonography as an ongoing clinical study. The findings at surgery were compared with the ultrasonographic findings. There were no false-positive, 8 false-negative, 9 true-positive, and 11 true-negative results. The specificity was $100 \%$ and sensitivity, $52.9 \%$ The findings of this study, in contrast to findings of other recently reported studies, demonstrates that ultrasonography is a poor modality with which to evaluate acute appendicitis.

(Key words: Diagnosis, ultrasonography, acute appendicitis)

Acute appendicitis is the most common cause of emergency abdominal surgery in the Western world. ${ }^{1}$ The diagnosis of acute appendicitis can be difficult to ascertain. The accepted false-positive rate is $15 \%$ to $20 \% .^{2}$

One third of all patients with acute appendicitis have atypical symptoms. ${ }^{3}$ In women of child-bearing age, the clinical presentation can be quite variable. Numerous patients with gynecologic abnormalities have signs and symptoms similar to those of acute appendicitis. The

From the Department of General Surgery, Garden City Osteopathic Hospital, Garden City, Mich, where, at the time this article was written, Dr Shinbrot was a resident. Dr Miller is residency director. Dr Shinbrot currently is completing his general surgery residency at Peninsula Hospital Center, Far Rockaway, NY, and St Barnabas Hospital, Bronx, N Y.

Reprint requests to Richard G. Shinbrot, DO, 21 Chapel Pl, Apt 2B, Great Neck, NY 11021. negative appendectomy rate in menstruating women has been reported to be as high as $34 \%$ to $40 \%$. $^{4}$

Several investigations attempting to facilitate the diagnosis and eliminate the accepted $15 \%$ to $20 \%$ false-positive rate have had little success. Plain abdominal radiographs showing an appendicolith account for $7 \%$ to $14 \%$ of falsepositive diagnoses. ${ }^{1,5,6}$ Barium enema examination is limited in its usefulness because a negative diagnosis is contingent on barium filling the appendix. The accuracy of a barium enema is approximately $50 \% .^{7}$ A computed tomography scan has been found to be of little diagnostic value because it is dependent on the presence of fluid in the right lower quadrant or the formation of an abscess, rather than direct visualization of the appendix. ${ }^{8}$ Laparoscopy has been disappointing because of the need for general anesthesia, its limited yield in patients with previous abdominal surgeries, the poor visualization of a retrocecal appendix, and its obvious invasiveness. ${ }^{9}$

Recent reports contend that high resolution ultrasonography, with graded compression to shift bowel gas, is a promising aid in the diagnosis of acute appendicitis. Specificity and sensitivity as high as $100 \%$ and $89 \%$, respectively, have been reported in the literature. ${ }^{4,10-12}$ We have reviewed 31 patients (including ten control subjects) who underwent graded compression ultrasonography before surgery for acute appendicitis.

\section{Materials and methods}

Between July 17, 1988 and June 30, 1989, a total 

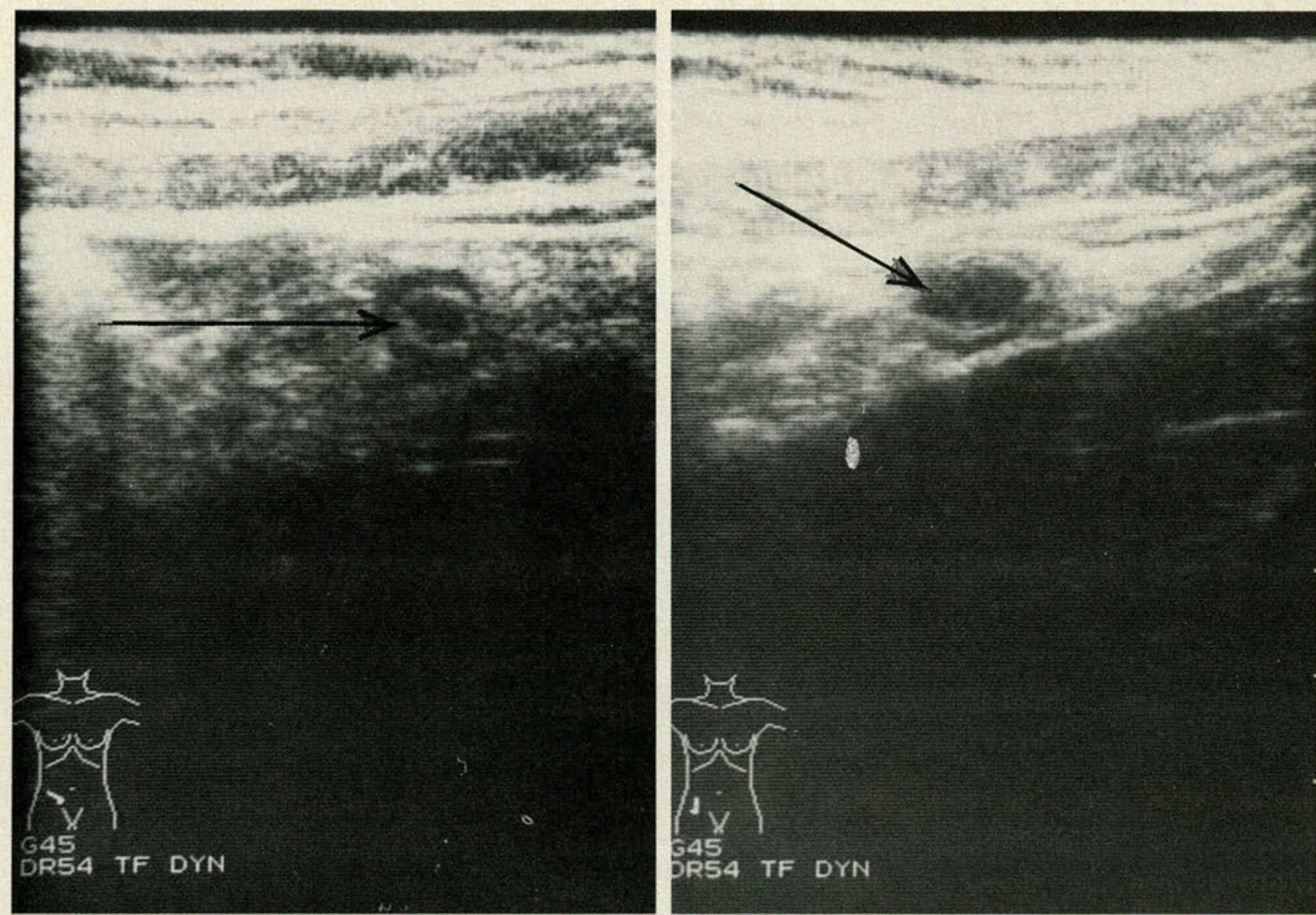

Figure 1. Arrows represent an appendicitis echo. The appendix appears as a cystic echo surrounded by a strong echo.

of 21 patients ( 12 women, 9 men; average age, 30.8 years) with a clinical diagnosis of acute appendicitis underwent ultrasonographic examination of the right lower quadrant. Because most appendectomies were performed in the evening, practicality limited patient selection to those reaching the hospital between $7 \mathrm{AM}$ and $4 \mathrm{PM}$. All emergency room patients suspected of having acute appendicitis were initially evaluated by a junior or senior surgical resident under the direct supervision of an attending physician.

Evaluation was based on a careful history, thorough physical examination, and appropriate laboratory workup. Laboratory workup included a complete blood cell (CBC) count and urinalysis and evaluations of serum electrolytes and serum amylase. The radiologic examination included radiographs of the abdomen with the patient in both the supine and standing positions, with a posteroanterior view of the chest.

Equivocal cases were admitted to the 24-hour observation area. The surgical resident and attending physician periodically reevaluated the patients' condition by serial abdominal checks, CBC counts, and radiologic examination.

After the clinical diagnosis of acute appendicitis was made, each patient underwent graded compression ultrasonography of the right lower quadrant as described by Puylaert and associates. ${ }^{10,13}$ A General Electric RT 3600 ultrasound machine with 5.0 and $7.5 \mathrm{MHz}$ linear array transducers was used. Examination was performed by a trained ultrasonography technician in the presence of an attending radiologist or the chief resident in radiology.

The transducer was handled in such a way that the abdomen was compressed with both hands to simulate manual palpation. The transducer was then introduced onto the abdomen between the palpating hands. This maneuver reduces gas artifacts by displacing bowel gas and shortens the distance between the transducer and the appendix. ${ }^{10}$ Scanning was begun directly over McBurney's point to include the region of maximal tenderness and adjacent regions of the right lower quadrant.

Results interpreted by the attending radiologist 
were reported as either "appendix visualized and inflamed" or "appendix not visualized." Visualization of the appendix is consistent with a noncompressible, immobile, echoic lumen surrounded by an echogenic mucosa (Fig 1 ). The radiologist's report also described "abscess of the appendix" when a well-circumscribed, encapsulated lesion filled with fluid was demonstrated.

Results of the ultrasonographic examination were not revealed to the surgeon until after the appendectomy was completed. The purpose of this study was to evaluate the sensitivity and specificity of ultrasonography, not to influence clinical management. Ultrasonographic findings were then compared with gross findings at surgery and with pathologic findings.

The control group consisted of ten randomly selected healthy subjects who had no abdominal complaints consistent with acute appendicitis. The average age of patients in the control group was 21.3 years. The group consisted of 13 women and 7 men. In every case, ultrasonographic findings were normal.

\section{Results}

Acute appendicitis was found in 17 $(80.9 \%)$ of the 21 patients in the study. Nine $(52.9 \%)$ of the 17 patients with appendicitis had an appendix echo visualized on ultrasonograms. There were no patients with an abnormal ultrasonographic finding who did not have acute appendicitis. Pathologic confirmation was obtained in all cases of acute appendicitis.

Of the nine patients with abnormal ultrasonograms, one had an appendiceal perforation with abscess formation, 2 had a perforated appendix with isolated pus in the abdomen with no abscess formation, 2 had a retrocecal appendix without perforation, and 4 had acute appendicitis with the appendix in the normal anatomic position (Table 1). One of the two retrocecal appendixes without perforation showed early gangrenous changes.
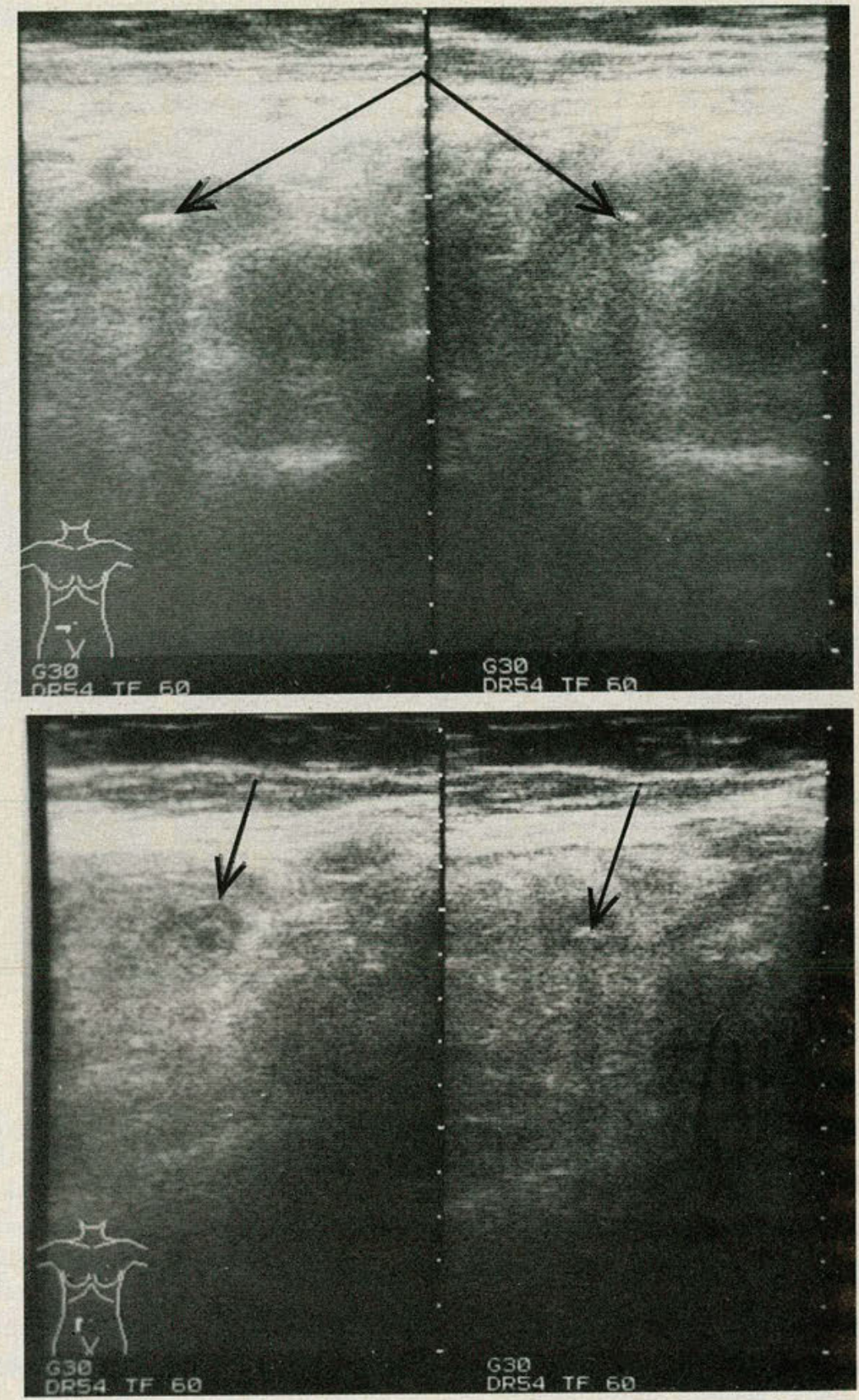

Figure 2. Arrows represent an appendicitis echo as in Figure 1, along with an area of small calcification in the center which represents an appendicolith. 
celiotomy, three were found to have enlarged mesenteric lymph nodes consistent with mesenteric lymphadenitis. The remaining patient had no gross surgical pathologic condition and was believed to have an acute gastroenteritis mimicking appendicitis.

Eight patients with normal ultrasonograms were found to have acute appendicitis. Among these eight, 1 had an appendiceal perforation with abscess formation, 1 had a perforated appendix with isolated pus in the abdomen with no abscess formation, 3 had a retrocecal appendix without perforation, 1 had a retrocecal appendix with perforation with abscess, and 2 had acute appendicitis with the appendix in the normal anatomic position (Table 1). One appendix showed early gangrenous changes.

Two of the 17 patients with acute appendicitis $(11.8 \%)$ had an appendicolith visualized on abdominal $x$-ray films taken in the supine and standing positions. One of these two patients had an inflamed appendix with an appendicolith visualized on an ultrasonogram. The second patient had neither the appendix nor the appendicolith visualized ultrasonographically. An appendicolith is associated with perforation of the appendix in $50 \%$ of cases. ${ }^{6}$ The sonographic appearance of an appendicolith (Fig 2) can be mimicked by intraluminal air, mucus, and fecal material. ${ }^{10}$

Puylaert and colleagues ${ }^{10,13}$ describe the ultrasonographic examination as causing mini-

\begin{tabular}{|c|c|c|}
\hline \multicolumn{3}{|c|}{$\begin{array}{l}\text { Table 1 } \\
\text { Pathologic and Ultrasonographic Findings in } \\
\text { Patients With Acute Appendicitis }\end{array}$} \\
\hline \multirow[b]{2}{*}{ Finding } & \multicolumn{2}{|c|}{ trasonographic finding } \\
\hline & $\begin{array}{c}\text { No. } \\
\text { positive }\end{array}$ & $\begin{array}{c}\text { No. } \\
\text { negative }\end{array}$ \\
\hline $\begin{array}{l}\text { Perforation with abscess } \\
\text { ( } 2 \text { patients) }\end{array}$ & 1 & 1 \\
\hline $\begin{array}{l}\text { Perforation without abscess } \\
\text { (3 patients) }\end{array}$ & 2 & 1 \\
\hline $\begin{array}{l}\text { Retrocecal appendix without } \\
\text { perforation ( } 5 \text { patients) }\end{array}$ & 2 & 3 \\
\hline $\begin{array}{l}\text { Retrocecal appendix with } \\
\text { perforation with abscess } \\
\text { (1 patient) }\end{array}$ & 0 & 1 \\
\hline $\begin{array}{l}\text { Acute appendicitis without } \\
\text { perforation ( } 6 \text { patients) }\end{array}$ & 4 & 2 \\
\hline
\end{tabular}

mal discomfort to the patient. All patients in this study tolerated the examination well, and the procedure was performed with little inconvenience.

\section{Discussion}

In this study, the sensitivity and specificity of the ultrasonographic procedure were $53 \%$ and $100 \%$, respectively. The positive predictive value and the negative predictive value were $100 \%$ and $33 \%$, respectively. The accuracy rate was $62 \%$ (Table 2 ).

Clearly, a discrepancy exists between the results reported in this paper and those in the

Table 2

Summary of Present and Previous Studies Using Ultrasonography To Evaluate Acute Appendicitis

\begin{tabular}{|c|c|c|c|c|c|}
\hline \multirow[b]{2}{*}{ Variable } & \multicolumn{5}{|c|}{ Authors } \\
\hline & $\begin{array}{c}\text { Shinbrot } \\
\text { and Miller } \\
\text { (1992) }\end{array}$ & $\begin{array}{c}\text { Jeffrey } \\
{\text { et } \mathrm{al}^{4}}^{(1987)}\end{array}$ & $\begin{array}{c}\text { Abu-Yousef } \\
{\text { et } \mathbf{a l}^{8}}^{(1987)}\end{array}$ & $\begin{array}{c}\text { Puylaert }^{10} \\
\text { (1986) }\end{array}$ & $\begin{array}{l}\text { Jeffrey } \\
{\text { et } \mathrm{al}^{11}}^{(1988)}\end{array}$ \\
\hline Sensitivity, \% & 53 & 89 & 80 & 89 & 90 \\
\hline Specificity, \% & 100 & 95 & 95 & 100 & 96 \\
\hline Positive predictive value, $\%$ & 100 & 89 & 91 & 89 & 93 \\
\hline Negative predictive value, $\%$ & 33 & 95 & 89 & 91 & 94 \\
\hline Accuracy, $\%$ & 62 & 93 & 90 & 95 & 94 \\
\hline
\end{tabular}


current literature (Table 2). The explanation for this discrepancy may be based on several factors. Although ultrasonography may be performed with great care, radiologists may have varying degrees of experience in interpreting results of this nature. Although graded compression was performed, residual bowel gas could have significantly altered the visualization of a sound image of the appendix.

There is considerable agreement on the specificity of the procedure in our study $(100 \%)$ and in other recently reported studies $(95 \%$ to $100 \%)^{4,10-12}$ There were no false-positive findings in our study. Therefore, if an inflamed appendix is visualized on an ultrasonogram, one can safely assume that acute appendicitis is present.

Niekel and associates ${ }^{14}$ found an alarmingly high false-negative rate (30\%) on ultrasonographic examination. Our investigation showed a consistently high false-negative value of $47 \%$ (Table 5). Therefore, as expressed by Karstrup and coworkers, ${ }^{15}$ nonvisualization of an echopoor/echo-free lesion does not exclude the presence of an inflamed appendix.

The retrocecal appendix in this study was visualized in only two $(33 \%)$ of six patients. Puylaert and associates ${ }^{13}$ state that the retrocecal appendix can probably be visualized with firm compression, but we did not find this to be the case.

\section{Conclusion}

Universal experience with, and acceptance of, this new-found diagnostic aid has yet to be achieved. The challenge resides in making the diagnosis of acute appendicitis early, accurately, and effectively, before perforation and its various complications ensue. The purpose of right lower quadrant ultrasonography should be to reduce the negative exploration rate when considering the diagnosis of acute appendicitis. Within this hospital setting, the ultrasonographic examination was found to be of little diagnostic benefit. Most studies referenced here have found the opposite to be true.

When considering any diagnostic test, the results are only as good as the interpreter. Be- fore one can start basing a classically historical clinical diagnosis on modern technology, more experience, training, and experimentation are needed.

Appendicitis demands a thorough workup and clinical evaluation. There is no substitute for the experienced surgeon's skill as both a diagnostician and a clinician. As stated by Schwartz, ${ }^{16}$ "Emphasis on technology at the expense of clinical evaluation will diminish, rather than improve, the quality of care of patients with acute abdominal pain."

\section{References}

1. Poole GV: Appendicitis: The diagnostic challenge continues. Am Surg 1988;54:609-612.

2. A sound approach to the diagnosis of acute appendicitis, editorial Lancet 1987;1:198-200.

3. Lewis FR, Holcroft JW, Boey J, et al: Appendicitis: A critical review of diagnosis and treatment in 1,000 cases. Arch Surg 1975;110:677-684.

4. Jeffrey RB Jr, Laing FC, Lewis FR: Acute appendicitis: Highresolution real time ultrasonography findings. Radiology 1987;163:11-14.

5. Shimkin PM: Radiology of acute appendicitis. Am J Radiol 1978;131:1001-1004.

6. Tegtmeyer CJ, Thistlethwaite JR, Sneed TF: Roentgen findings in acute appendicitis. Med Ann 1969;38:127-130.

7. Fedyshin P, Kelvin FM, Rice RP: Nonspecificity of barium enema findings in acute appendicitis. Am J Radiol 1984;143:99. 102.

8. Abu-Yousef MM, Bleicher JJ, Maher JW, et al: High-resolution sonography of acute appendicitis. Am J Radiol 1987;149:53. 58.

9. Leape LL, Ramenofsky ML: Laparoscopy for questionable appendicitis: Can it reduce the negative appendectomy rate? Ann Surg 1980;108:336-337.

10. Puylaert JBCM: Acute appendicitis: ultrasonography evaluation using graded compression. Radiology 1986;158:355-360. 11. Jeffrey RB, Laing FC, Townsend RR: Acute appendicitis: Sonographic criteria based on 250 cases. Radiology 1988;167:327329 .

12. Gisler M, Rouse G, DeLange M: Sonography of appendicitis: A review. JDMS March/April 1989;2:57-60.

13. Puylaert JBCM, Rutgers $\mathrm{PH}$, Lalisang RI, et al: A prospective study of ultrasonography in the diagnosis of appendicitis. N Engl J Med 1987;317:666-669.

14. Niekel RAM, Lampmann LEH: Graded compression sonography in acute appendicitis. Fortschr, Röntgenstr 1986;145(4):441445.

15. Karstrup S, Torp-Pedersen S, Roikjaer O: Ultrasonic visualization of the inflamed appendix. $B r J$ Radiol 1986;59:985986.

16. Schwartz SI: Tempering the technological diagnosis of appendicitis. N Engl J Med 1987;317:703-704. 